
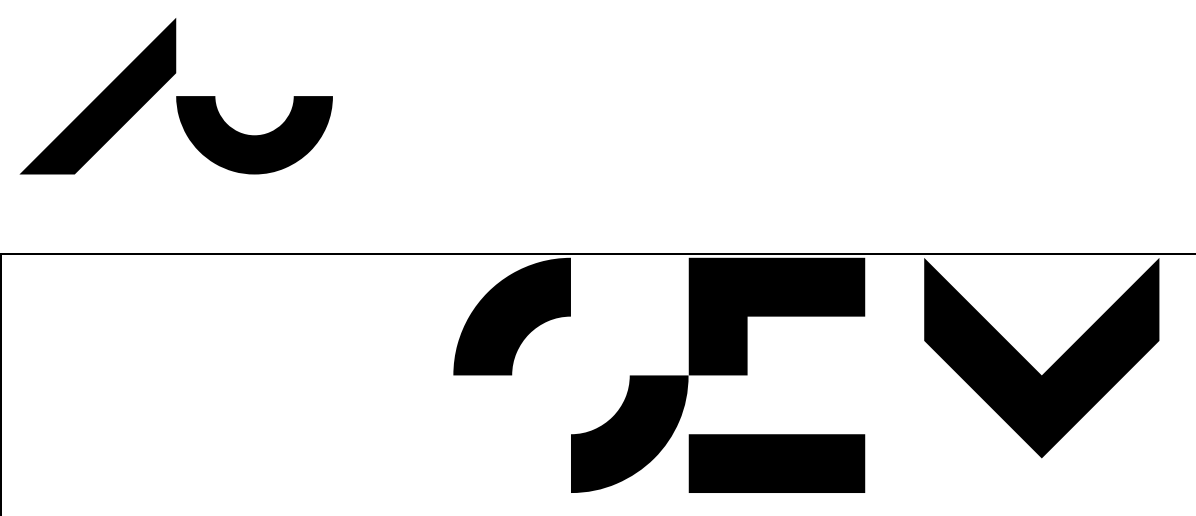

Economics Working Paper

2010-10

\title{
Ad valorem versus unit taxes: Monopolistic competition, heterogeneous firms, and intra- industry reallocations
}

Philipp J.H. Schröder and Allan Sørensen

Bartholins Allé 10, Building 1322

DK-8000 Aarhus C - Denmark

Phone +4589421610

Mail: oekonomi@econ.au.dk

Web: www.econ.au.dk 

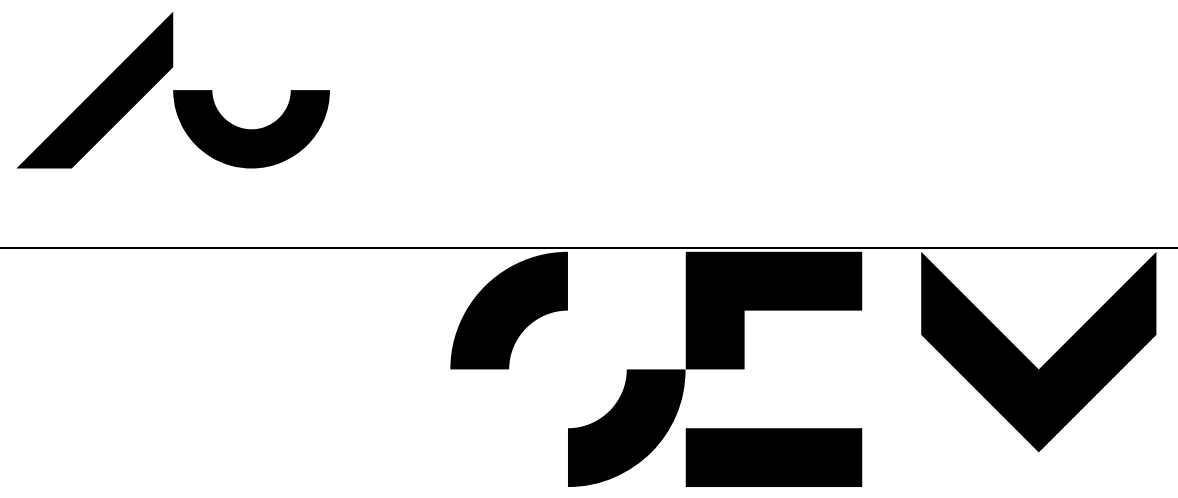

\section{Economics Working Paper}

2010-10

School of Economics and Management

Aarhus University

Bartholins Allé 10, Building 1322

DK-8000 Aarhus C - Denmark

Phone +4589421610

Mail: oekonomi@econ.au.dk

Web: www.econ.au.dk 


\title{
Ad valorem versus unit taxes: Monopolistic competition, heterogeneous firms, and intra-industry reallocations
}

\author{
Philipp J.H. Schröder* Allan Sørensen ${ }^{\dagger}$
}

June 2010

\begin{abstract}
Real-world industries are composed from heterogeneous firms and substantial intra-industry reallocations take place, i.e. high productivity firms squeeze out low productivity firms. Previous tax-tool comparisons have not included these central forces of industry structure. This paper examines a general equilibrium monopolistic competition model with heterogeneous firms and intra-industry reallocations. We show that the welfare superiority of ad valorem over unit taxes under imperfect competition is not only preserved but amplified. The additional difference between the tools arises because unit taxes distort relative prices, which in turn reduces average industry productivity through reallocations (the survival and increased market share of lower productivity firms). Importantly, numerical solutions of the model reveal that the relative welfare loss from using the unit tax increases dramatically in the degree of firm heterogeneity.
\end{abstract}

JEL-codes: D43, D61, H21, H22, H23, L11, L13

Keywords: unit tax, ad valorem tax, welfare, intra-industry reallocation, monopolistic competition, heterogenous firms

\footnotetext{
* Department of Economics, Aarhus School of Business, Aarhus University, Denmark. Tel.: +458948 6392, Fax: +45 8948 6197, E-mail: psc@asb.dk.

†School of Economics and Management, Aarhus University, Denmark. Tel.: + 4589421573 , E-mail: asoerensen@econ.au.dk.
} 


\section{Introduction}

Is an ad valorem tax preferable to an equal-yield unit tax? It is well-known that the choice is irrelevant for competitive markets, since here the two tax instruments are equivalent. For the more realistic case of imperfect competition, a sizable literature, starting with Wicksell (1896), has shown that ad valorem taxes are welfare superior to equal-yield unit taxes; see e.g. Suits and Musgrave (1953), Delipalla and Keen (1992) or Keen (1998) for a review of the literature. ${ }^{1}$ A central contribution to this literature is Anderson et al. (2001), who examine the cases of oligopoly with entry/exit and find - in line with previous literature - that an ad valorem tax is preferable when firms are either homogenous or compete in quantities. However, Anderson et al. (2001) also find for the Bertrand case - as did more recently Wang and Zhao (2009) for the Cournot case with high degrees of product differentiation - that unit taxes may welfare dominate ad valorem taxes when firms are sufficiently heterogenous. These findings, of reverse welfare rankings, by them self call for further tax tool comparisons in other settings with heterogeneous firms.

More importantly and central to the present paper, strong empirical evidence suggests, that in addition to the mere existence of firm heterogeneity, i.e. persistent size and productivity differences among the firms of an industry, such firm heterogeneity is a key driver of intra-industry reallocations. Heterogeneity in say firm-level productivity can, paired with firm-level uncertainty, not only explain the empirically relevant simultaneous entry and exit into sectors, but it can also explain the sizable intra-industry reallocations observed in modern economies. Resources and activity are continuously shifted from exiting or shrinking firms to new and expanding ones (see e.g. Dunne et al., 1989).

These central stylized facts of industrial economics have been reconciled with theory in a path-breaking modeling approach, pioneered by Hopenhayn (1992), that examines stationary long-run equilibria (providing the equivalent of a steady state equilibrium for an inherently dynamic system) allowing for firm heterogeneity, uncertainty, and intra-industry reallocations. This class of models can capture the structural characteristics of an industry, such as the size and distribution of firms, and how they react to the parameters of the model, but has - to the best of our knowledge - not previously been applied to the tax tool analysis in public economics.

The present paper fills this gap. We provide a general equilibrium Hopenhayn (1992)-type model combined with Dixit-Stiglitz (1977)-type monopolistic competition. To be explicit, the seminal Hopenhayn (1992) paper is cast in a homogeneous products market structure with price-taking firms. By employing Dixit-Stiglitz (1977) monopolistic competition, we include product differentiation, CES preferences and mark-up pricing. Moreover, while Hopenhayn (1992)

\footnotetext{
${ }^{1}$ The ranking of the two tax tools under imperfect competition can also be inverted, for example in the presence of externalities (e.g. Pirttilä, 2002), in the case of monopsony (e.g. Hamilton, 1999), or when departing from the equal-yield criterion (e.g. Dröge and Schörder, 2009) and welfare equivalence can be reestablished for a monopoly sector embedded in a general equilibrium model with $100 \%$ profit taxation (e.g. Blackorby and Murty, 2007).
} 
models continuous productivity shocks throughout a firms lifetime, we only include pre-entry uncertainty about firm productivity. Thus in effect, the model used here is a closed economy version of what has become the new workhorse model of international trade: Melitz (2003). In these models one can capture all the resulting intra-industry reallocations resulting from changes in the parameters of the model. Under standard assumptions this framework remains highly tractable, such that we are able to conduct a comprehensive analysis of the welfare effects of ad valorem and unit taxes; although, the introduction of unit taxes reduces tractability somewhat. The increased complexity when including a unit tax derives from a distortion of relative market prices and thus market shares. However, exactly these distortions drive our new finding on the interaction between taxes and industry structure. The industry average productivity effects from intra-industry reallocations caused by the application of different tax tools have not previously been identified in the tax literature.

We find that the usual welfare dominance of ad valorem taxes over unit taxes ensues in this setting of heterogeneity and intra-industry reallocations, albeit for novel and interesting reasons. Earlier, Schröder (2004) has confirmed the traditional ranking in a Dixit-Stiglitz (1977)-type monopolistic competition setting (with homogeneous firms and without intra-industry reallocations). In Schröder (2004), the larger tax over-shift from the unit tax drives the result. We show that with heterogeneity and reallocations the welfare superiority of ad valorem taxes to an equal-yield unit tax is no longer solely driven by the larger tax over-shift of the unit tax, but also from the distortion of relative costs and thus a distorted price and industry structure induced by the unit tax instrument. We find that the unit tax reduces average productivity - and thus welfare - compared to an equal-yield ad valorem tax, because it boosts the relative market share of lower productivity firms and permits relatively less productive firms to survive in the industry. Thus, unit taxes push the resources of the economy to less efficient producers. These findings command important new policy implications: Numerical solutions of our model suggest that the relative welfare gain from using the ad valorem tax instrument increases in the degree of firm heterogeneity. Moreover, this effect is important in size: when firms are sufficiently heterogenous the effect of distorted relative prices is an order of magnitude larger than the effect from the larger tax over-shift.

Apart from being the first paper to conduct the ad valorem versus unit tax comparison in a Hopenhayn (1992)-type model with firm heterogeneity and intra-industry reallocation, the present work is embedded in several strands of recent literature. The aforementioned Schröder (2004) provides the same taxtool comparison, but remains within the standard Dixit-Stiglitz setting with homogeneous firms, and ignoring intra-industry reallocations and establishes the traditional tax tool ranking. Doi and Futagami (2004), develop a general equilibrium model with variety preferences (but not CES preferences) and study the ability of unit taxes to optimize the number of firms in equilibrium; a comparison to ad valorem taxes is not conducted and firms are homogeneous in their setting. A recent comparison of ad valorem and unit taxes is provided in a macro-type general equilibrium model by Torregrosa (2008). But here firms are 
homogeneous and the paper departs from the equal yield criterion in order to focus on tax reform issues. Finally, the above mentioned papers by Anderson et al. (2001) and Wang and Zhao (2009) include heterogeneous firms and identify situations with the inverse welfare ranking of the two tax tools. Anderson et al. (2001) find the inverse ranking for a long-run (free entry/exit) Bertrand oligopoly with heterogeneous firms; while Wang and Zhao (2009) find - in the presence of substantial firm heterogeneity and product differentiation - the inverse ranking also for the Cournot case. Apart from applying a different mode of competition from the present Dixit-Stiglitz mode, none of these works capture the intra-industry reallocations and general equilibrium effects provided in the present paper.

The rest of the paper is organized as follows. Section 2 describes the general equilibrium monopolistic competition model with heterogenous firms including unit and ad valorem taxes. In this section we also derive the results on industry structure (reallocation) and average productivity. Section 3 ranks equal-yield ad valorem and unit taxes. Section 4 contains numerical solutions of the model to provide insights on the quantitative importance of firm heterogeneity and intra-industry reallocation effects. Section 5 concludes. An appendix provides additional technical detail.

\section{The model}

We consider a special version of the seminal Hopenhayn (1992) model, where we include Dixit-Stiglitz (1977) monopolistic competition and pre-entry uncertainty about firm-specific marginal productivity. This is in effect a closed economy version of the popular intra-industry trade model of Melitz (2003). In this setting we derive and compare the effects of obtaining an exogenous tax revenue $(\hat{T})$ through either an ad valorem tax or a unit tax. We assume that tax revenue is used for public employment, but all results hold under the alternative assumption of lump-sum redistribution of tax revenues to households.

\section{Households}

The representative household supplies inelastic $L$ units of labour. Preferences of the representative household over a set of goods/varieties $(\Omega)$ are given by the CES aggregate

$$
U=\left[\int_{\omega \in \Omega} q(\omega)^{\frac{\sigma-1}{\sigma}} d \omega\right]^{\frac{\sigma}{\sigma-1}},
$$

where $q(\omega)$ is consumption of variety $\omega$ and $\sigma>1$ is the elasticity of substitution between any goods. Demand for each variety accordingly takes the form

$$
q(\omega)=\left(\frac{p(\omega)}{P}\right)^{-\sigma} \frac{E}{P},
$$


where $E$ denotes aggregate expenditures, $p(\omega)$ the price of variety $\omega$ and $P$ the price index of one unit of the composite good defined by

$$
P=\left[\int_{\omega \in \Omega} p(\omega)^{1-\sigma} d \omega\right]^{\frac{1}{1-\sigma}} .
$$

\section{Firms}

Monopolistic firms have constant but heterogenous marginal costs, and each firm produces only one variety, such that - as is custom in monopolistic competition models - firms and varieties are synonymous. Firms face sunk costs of developing a new variety, $F_{E}>0 .^{2}$ Each new variety is subsequently to its development randomly associated with a variety specific marginal productivity $(\varphi(\omega))$ and thus marginal costs that do not change over time. Production exhibits increasing returns, since firms face fixed costs of production, $F>0$. Moreover, firms are subject to both a unit $(t \geq 0)$ and an ad valorem tax $(\tau \geq 0)$. Due to symmetry in preferences, a firm is fully characterized by its individual marginal productivity and the firm/variety identity $\omega$ is suppressed in the following.

Using the demand relation (2) and normalizing the wage to unity, we can write profits as

$$
\pi(\varphi)=\left(\frac{p(\varphi)}{P}\right)^{-\sigma} \frac{E}{P}\left(\frac{p(\varphi)}{1+\tau}-\frac{1}{\varphi}-t\right)-F
$$

where $p(\varphi)$ is the price of the firm. Optimal pricing implies

$$
p(\varphi)=\frac{\sigma}{\sigma-1}(1+\tau)\left(\frac{1}{\varphi}+t\right) .
$$

Following the literature, we leave aside the analysis of complicated firmlevel adjustment processes, and instead we focus on steady state equilibria. The intertemporal discount rate is assumed to be zero and the present values of firms are kept finite by assuming that firms die with constant probability $\delta>0 .{ }^{3}$ Free entry ensures that firms enter until expected lifetime profits equal the costs of developing a new variety.

\section{Industry structure}

Inserting the optimal price (4) into the flow profit expression, we have

$$
\pi(\varphi)=B(1+\tau)^{-\sigma}\left(\frac{1}{\varphi}+t\right)^{1-\sigma}-F,
$$

\footnotetext{
${ }^{2}$ The costs consist of employing $F_{E}$ units of labour. However, as we set the wage $w$ to be the numeraire $(w \equiv 1)$, the costs equal $F_{E}$.

${ }^{3}$ By setting $\delta=1$, we would obtain a static model with the same qualitative properties as those of the steady states of the dynamic model presented here.
} 
where $B \equiv \frac{1}{\sigma-1}\left(\frac{\sigma}{\sigma-1}\right)^{-\sigma} P^{\sigma-1} E$. Flow profits increase in marginal productivity $\varphi$, fall in tax rates and due to the fixed costs of production only firms with sufficiently high productivity choose to produce in equilibrium. The least productive firm that actually starts production must have a productivity level, $\varphi^{*}$, such that it exactly breaks even:

$$
\pi\left(\varphi^{*}\right)=0 \Leftrightarrow B(1+\tau)^{-\sigma}\left(\frac{1}{\varphi^{*}}+t\right)^{1-\sigma}=F .
$$

In the following we denote by $\varphi^{*}$ the exit threshold. Firms that entered the industry but received a productivity below $\varphi^{*}$ will exit the industry (choosing not to start production) while those firms with higher productivity will produce and stay in the industry. Using the exit threshold relation (6) flow profits (5) can be written as

$$
\pi(\varphi)=F\left[\left(\frac{\frac{1}{\varphi}+t}{\frac{1}{\varphi^{*}}+t}\right)^{1-\sigma}-1\right]
$$

Free entry and exit ensures that firms enter the industry until the expected value of the stream of profits equals entry costs. Put differently, the expected value of the lottery of drawing a variety specific productivity must match the cost, $F_{E}$, of participating in the lottery. It is hence the uncertainty of not knowing ones exact productivity prior to entering the industry that matters. Let $G(\varphi)$ denote the cumulative distribution function from which random productivity is drawn, where $G$ is defined on $[0, \infty]$ with infinite support and no mass points and let $g(\varphi)=G^{\prime}(\varphi)$, then the free entry condition reads

$$
\int_{\varphi^{*}}^{\infty} \frac{\pi(\varphi)}{\delta} g(\varphi) d \varphi=F_{E} \Leftrightarrow \int_{\varphi^{*}}^{\infty}\left[\left(\frac{\frac{1}{\varphi}+t}{\frac{1}{\varphi^{*}}+t}\right)^{1-\sigma}-1\right] g(\varphi) d \varphi=\frac{\delta F_{E}}{F} .
$$

The following results can be stated:

Lemma 1 The free entry condition (7) uniquely determines the exit threshold, $\varphi^{*}\left(t, \frac{\delta F_{E}}{F}, \sigma\right)$

Proof. It follows from (7) that

$$
\frac{\partial \int_{\varphi^{*}}^{\infty}\left[\left(\frac{\frac{1}{\varphi}+t}{\frac{1}{\varphi^{*}}+t}\right)^{1-\sigma}-1\right] g(\varphi) d \varphi}{\partial \varphi^{*}}=-(\sigma-1) \frac{\frac{1}{\varphi^{*}} \frac{1}{\varphi^{*}}}{\frac{1}{\varphi^{*}}+t} \int_{\varphi^{*}}^{\infty}\left[\left(\frac{\frac{1}{\varphi}+t}{\frac{1}{\varphi^{*}}+t}\right)^{1-\sigma}\right] g(\varphi) d \varphi<0,
$$

implying that the left-hand side of (7) is continuous and decreasing. Moreover, note that $\lim _{\varphi^{*} \rightarrow \infty} \int_{\varphi^{*}}^{\infty}\left[\left(\frac{\frac{1}{\varphi}+t}{\frac{1}{\varphi^{*}}+t}\right)^{1-\sigma}-1\right] g(\varphi) d \varphi=0$ and that 
$\lim _{\varphi^{*} \rightarrow 0} \int_{\varphi^{*}}^{\infty}\left[\left(\frac{\frac{1}{\varphi}+t}{\frac{1}{\varphi^{*}}+t}\right)^{1-\sigma}-1\right] g(\varphi) d \varphi=\infty$. Hence there is a unique solution to $(7)$

While the principles of the above results are standard findings in the Hopenhayn (1992)-based literature, e.g. Melitz (2003), the distinct effects of the two tax tools, $\tau$ and $t$, have not previously been identified. In particular, from the free entry conditions (7) we can establish that the unit tax has an impact on the exit threshold, while the ad valorem tax does not. We have that

Proposition 1 A unit tax distorts the industry structure whereas an ad valorem tax is neutral on the industry structure. In particular, a higher unit tax reduces the exit threshold and thereby allows less productive firms to survive.

Proof. From the free entry condition (7), it follows that

$$
\frac{d \varphi^{*}}{d t}=-\frac{\int_{\varphi^{*}}^{\infty}\left[\left(\frac{1}{\varphi}+t\right)^{-\sigma} \frac{\varphi-\varphi^{*}}{\varphi}\right] g(\varphi) d \varphi}{\int_{\varphi^{*}}^{\infty}\left[\left(\frac{1}{\varphi}+t\right)^{1-\sigma} \frac{1}{\varphi^{*}}\right] g(\varphi) d \varphi}<0 \text { and } \frac{d \varphi^{*}}{d \tau}=0 .
$$

Proposition 1 states that a unit tax allows less productive firms to survive whereas this does not apply to the ad valorem tax. This survival of less productive firms occurs as the unit tax is homogenous across firms and therefore reduces the dispersion in relative prices, cf.

$$
\frac{p(\varphi)}{p\left(\varphi^{\prime}\right)}=\frac{\frac{\sigma}{\sigma-1}(1+\tau)\left(\frac{1}{\varphi}+t\right)}{\frac{\sigma}{\sigma-1}(1+\tau)\left(\frac{1}{\varphi^{\prime}}+t\right)}=\frac{\varphi^{\prime}}{\varphi} \frac{1+\varphi t}{1+\varphi^{\prime} t}
$$

Less dispersion in relative prices in turn implies less dispersion in market shares and relative profits. Hence, the unit tax shifts profits from high productivity firms towards low productivity firms and this allows less productive firms to survive.

Next, consider average productivity defined as production weighted average productivity

$$
\bar{\varphi} \equiv \frac{\int_{\varphi^{*}}^{\infty} \varphi q(\varphi) \mu(\varphi) d \varphi}{\int_{\varphi^{*}}^{\infty} q(\varphi) \mu(\varphi) d \varphi}=\frac{\int_{\varphi^{*}}^{\infty} \varphi\left(\frac{1}{\varphi}+t\right)^{-\sigma} g(\varphi) d \varphi}{\int_{\varphi^{*}}^{\infty}\left(\frac{1}{\varphi}+t\right)^{-\sigma} g(\varphi) d \varphi},
$$

where $\mu(\varphi)=\frac{g(\varphi)}{1-G\left(\varphi^{*}\right)}$ is the density of marginal productivities among active firms. We can state: 
Proposition $2 A$ unit tax reduces average productivity and an ad valorem tax has no effect on average productivity.

Proof. See the appendix.

The unit tax reduces average productivity because it shifts market shares and thus production from high productivity firms towards low productivity firms among a given population of active firms, $\frac{\partial \bar{\varphi}}{\partial t}<0$ (cf. the proof of Proposition 2 in the appendix). In addition, a unit tax also allows less productive firms to survive which further reduces average productivity, $\frac{\partial \bar{\varphi}}{\partial \varphi^{*}} \frac{d \varphi^{*}}{d t}<0$ (cf. the proof of Proposition 2 in the appendix). However, an ad valorem tax does not distort relative prices and is therefore neutral on industry structure and has no effect on average productivity.

\section{Aggregation}

The market clearing condition is that total sales at market prices (including taxes) must equal total expenditure/income. In this setting with an intertemporal discount rate of zero, there are no returns to savings (investments in sunk costs) and since aggregate profits are driven to zero by the free entry condition, total income equals labour income which due to the normalization of the wage rate simply equals the exogenous labour supply, i.e. $E=L$. The aggregated (total) sales at market prices are:

$$
M \int_{\varphi^{*}}^{\infty} q(\varphi) p(\varphi) \mu(\varphi) d \varphi
$$

where $M$ denotes the endogenous mass of firms. Using (2) and (4), the market clearing condition reads

$$
M=\frac{L}{\sigma F} \frac{1}{(1+\tau)} \frac{1}{\left(\frac{1}{\varphi^{*}}+t\right)^{\sigma-1} \int_{\varphi^{*}}^{\infty}\left(\frac{1}{\varphi}+t\right)^{1-\sigma} \mu(\varphi) d \varphi} .
$$

Using optimal prices (4) and the mass of firms (9) we can write the price index (3) as

$$
P=\frac{\sigma}{\sigma-1}\left(\frac{L}{\sigma F}\right)^{\frac{1}{1-\sigma}}(1+\tau)^{\frac{\sigma}{\sigma-1}}\left(\frac{1}{\varphi^{*}}+t\right) .
$$

Using (2), (4) and (9), aggregate tax revenue is given by

$$
\begin{aligned}
T & =M \int_{\varphi^{*}}^{\infty} q(\varphi)\left[t+\frac{\tau}{1+\tau} p(\varphi)\right] \mu(\varphi) d \varphi \\
& =L\left[\frac{\sigma-1}{\sigma} \frac{t}{1+\tau} \frac{\int_{\varphi^{*}}^{\infty}\left(\frac{1}{\varphi}+t\right)^{-\sigma} \mu(\varphi) d \varphi}{\int_{\varphi^{*}}^{\infty}\left(\frac{1}{\varphi}+t\right)^{1-\sigma} \mu(\varphi) d \varphi}+\frac{\tau}{1+\tau}\right] .
\end{aligned}
$$


Finally, welfare from private consumption (recall that aggregated industry profits are competed to zero by entry/exit) is given by

$$
U=\frac{E}{P}=\frac{\sigma-1}{\sigma} L\left(\frac{L}{\sigma F}\right)^{\frac{1}{\sigma-1}}(1+\tau)^{-\frac{\sigma}{\sigma-1}}\left(\frac{1}{\varphi^{*}}+t\right)^{-1}
$$

\section{Welfare comparison of equal-yield unit and ad valorem taxes}

Financing the exogenous tax revenue constraint $\hat{T}$ by an ad valorem tax requires, cf. the aggregate tax revenue relation (10), that

$$
\hat{T}=L \frac{\tau}{1+\tau} \Leftrightarrow \tau=\frac{\frac{\hat{T}}{L}}{1-\frac{\hat{T}}{L}} .
$$

Similarly, the required unit tax is defined by

$$
\begin{aligned}
\hat{T} & =L\left[\frac{\sigma-1}{\sigma} t \frac{\int_{\varphi^{*}}^{\infty}\left(t, \frac{\delta F_{E}}{F}, \sigma\right)}{\int_{\varphi^{*}}^{\infty}\left(t, \frac{\delta F_{E}}{F}, \sigma\right)}\left(\frac{1}{\varphi}+t\right)^{-\sigma} \mu(\varphi) d \varphi\right. \\
& \Rightarrow t=t\left(\frac{\hat{T}}{L}, \sigma, \varphi^{*}\left(t, \frac{\delta F_{E}}{F}, \sigma\right)\right)=t\left(\frac{\hat{T}}{L}, \sigma, \frac{\delta F_{E}}{F}\right) .
\end{aligned}
$$

Letting $U^{t}\left(U^{\tau}\right)$ denote welfare when financing the revenue constraint through a unit tax (an ad valorem tax), our central relative welfare expression becomes

$$
\frac{U^{\tau}}{U^{t}}=\frac{\left(1-\frac{\hat{T}}{L}\right)^{\frac{\sigma}{\sigma-1}} \varphi^{*}\left(0, \frac{\delta F_{E}}{F}, \sigma\right)}{\left(\frac{1}{\varphi^{*}\left(t\left(\frac{\hat{T}}{L}, \sigma, \frac{\delta F_{F}}{F}\right), \frac{\delta F_{E}}{F}, \sigma\right)}+t\left(\frac{\hat{T}}{L}, \sigma, \frac{\delta F_{E}}{F}\right)\right)^{-1}} .
$$

By $\frac{U^{\tau}}{U^{t}}$ we can establish the ranking of the two tax tools. Due to the price distortion stemming from the unit tax, this expression for relative welfare is cumbersome to analyze directly. However, we can establish our main result by considering the social planner solution. It turns out that the market equilibrium with an ad valorem tax coincides with the social planner solution and accordingly a universal welfare ranking can be established.

Proposition 3 The ad valorem tax instrument is more efficient in raising tax revenue than the unit tax instrument, i.e. $\frac{U^{\tau}}{U^{t}}>1$.

Proof. We show in the appendix that the market equilibrium with the ad valorem tax coincides with the social planner solution. This is not the case for the unit tax and thus establishes Proposition 3. 
Proposition 3 states the main result of the paper. Ad valorem taxes are more efficient in raising tax revenue than unit taxes in a monopolistic competition setting with constant elasticities of demand, heterogenous firms and intra-industry reallocations. This extends previous findings made in imperfect competition settings. In particular, this result complements existing literature that has derived the same ranking with homogenous firms (in various cases of imperfect competition including monopolistic competition with constant elasticities of demand) by extending to the case of heterogeneous firms. Moreover, driven by intra-industry reallocations, our finding also establishes that previous cases of an inverse welfare ranking made with cost heterogeneity (e.g. Anderson et al., 2001; Wang and Zhao, 2009) do not occur in the present framework of a Hopenhayn (1992)-type model. There are two sources that contribute to the welfare ranking established here. First, there is a larger tax over-shift for the unit tax, i.e. the previous finding of Schröder (2004) made in the homogenous firms monopolistic competition case. Second and a novel result for the tax tool ranking in the presence of firm heterogeneity, the unit tax distorts relative prices and thereby the industry structure which in turn reduces average productivity, cf. Proposition 2. In a setting with homogenous firms only the first source is present. Yet, in the empirically relevant setting of firm heterogeneity and intra-industry reallocations the second effect will take place.

\section{The degree of firm heterogeneity}

This section sheds light on the relative magnitude of the two sources of welfare gains from applying an ad valorem tax in stead of a unit tax identified above. We do so by computing relative welfare for various degrees of firm heterogeneity including the case of firms being homogenous. When firms are homogenous, we find (see the appendix for derivation)

$$
\frac{U^{\tau}}{U^{t}}=\frac{\left(1-\frac{\hat{T}}{L}\right)^{\frac{\sigma}{\sigma-1}}}{1-\frac{\hat{T}}{L} \frac{\sigma}{\sigma-1}}>1 \text { for } \hat{T}>0 .
$$

In order to compute relative welfare when firms are heterogenous, we have to assume a given distribution of marginal productivities. We follow the trade literature (see e.g. Helpman et al., 2004, and Chaney, 2007) by assuming that productivities are drawn from a Pareto distribution with location parameter $\varphi_{0}>0$ and shape parameter $k>\sigma-1$, i.e. the density function is given by ${ }^{4}$

$$
g(\varphi)=\left\{\begin{array}{cc}
k \varphi_{0}^{k} \varphi^{-k-1} & \varphi \geq \varphi_{0} \\
0 & \text { otherwise }
\end{array}\right.
$$

The Pareto distribution has two advantages. First, it approximates the distribution of firms found in empirical work (see e.g. Simon and Bonini, 1958, and more recently Axtell, 2001, and Luttmer, 2007). Second, it permits us to

\footnotetext{
${ }^{4}$ The restriction of $k>\sigma-1$ ensures finite expected flow profits.
} 
derive closed form solutions for the ad valorem tax, while we have to refer to simulation results for the unit tax, and hence relative welfare. Figure 1 shows relative welfare for the parameter values $L=1, F=0.2, F_{E}=0.1 \delta=0.1$, $\sigma=3, \frac{T}{L}=0.2$ and various levels of $k$ to trace the effect of firm heterogeneity. ${ }^{5}$

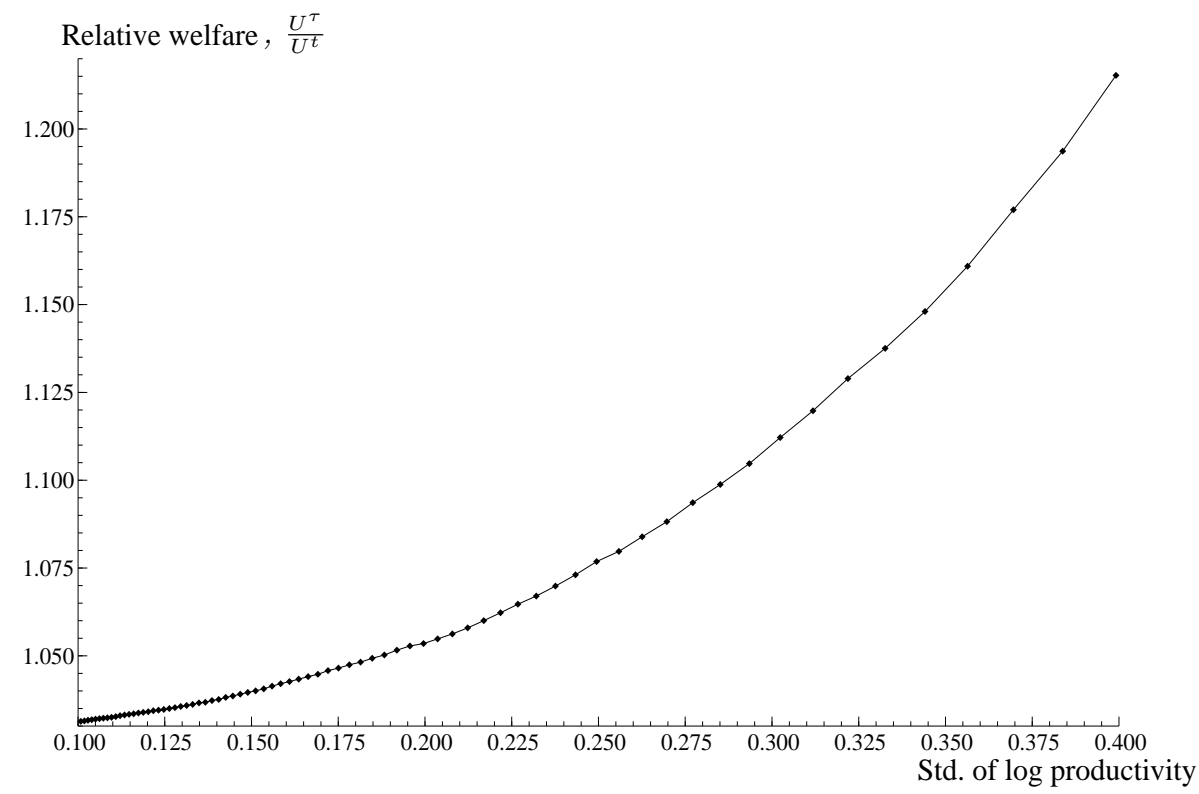

Figure 1: Relative welfare and firm heterogeneity

Figure 1 discloses that the welfare advantage of the ad valorem tax over the unit tax established in Proposition 3 increases in the degree of firm heterogeneity and that the overall welfare gain from using the ad valorem tax relative to the unit tax is quantitatively important. In fact the percentage-wise welfare gain from replacing unit with ad valorem taxes will for high degrees of firm heterogeneity exceed the welfare advantage of the homogeneous firms case (solely driven by differences in tax overshift) more than 10 -fold. ${ }^{6}$ Hence, the distortions of relative prices which impact on industry structure and average productivity must be taken into account when conducting the welfare ranking of tax instruments. This channel will matter for welfare ranking results in realistic imperfect competition settings, where firms are heterogeneous (differ in costs), products are differentiated, entry and exit occur and intra-industry reallocations take place.

\footnotetext{
${ }^{5}$ See the appendix for further details on the numerical computations.

${ }^{6}$ The homogeneous firms welfare ratio of the two tax tools is for the above numerical values $\frac{U^{\tau}}{U^{t}}=1.022$.
} 


\section{Conclusion}

The old question of ad valorem versus unit taxation has been revisited in a monopolistic competition model with heterogenous firms and intra-industry reallocations. This class of models is a step closer towards empirically relevant modes of competition and industry dynamics. The common finding of an ad valorem tax being welfare superior to an equal-yield unit tax is confirmed. The inclusion of firm heterogeneity, uncertainty and reallocations, identified a new contributor to this welfare ranking, namely our finding that the unit tax distorts relative prices and thereby the industry structure. The numerical solutions to the model suggest that this channel is quantitative important if firms are fairly heterogeneous. In fact, for the particular solutions presented this new channel dwarfs the previously established channel of tax over-shift under monopolistic competition (Schröder, 2004) when firms become sufficiently heterogenous.

According to the theory of second best, the rankings of generally distortionary tax instruments in settings of imperfect competition must depend on the interaction among the various imperfections. Therefore, no universal ranking of unit and ad valorem taxes under imperfect competition can be expected. Anderson et. al. (2001) exactly provide an example where the unit tax is the preferable tax instrument, which demonstrates that the ranking depends on the specific assumptions of the imperfect competition model. In the present framework a crucial assumption is that of CES preferences, since these preferences imply that the market equilibrium in the absence of a unit tax is first best. For other preferences this first best property of the market equilibrium with no unit taxes does not hold and thus the unit tax may become the preferable instrument in such situations. An important area for future research is thus the study of more flexible imperfect competition models in order to derive testable implications that can determine the welfare ranking of unit and ad valorem taxes.

Establishing a novel channel by which the design of tax tools matters for welfare outcomes commands potentially important policy implications. On the one hand, with firm heterogeneity and intra-industry reallocations unit taxes are more costly than previously thought because they affect the resulting industry structure and allow less efficient firms to survive in the industry. On the other hand, in those sectors where we observe the frequent use of unit taxes (e.g. tobacco, fuel), one could suspect a low degree of firm heterogeneity and thus a limited welfare cost from employing the unit tax tool. 


\section{A Appendix}

\section{Social planner solution}

The social planner maximizes utility (1) subject to using $\hat{T}$ units of the exogenous labour endowment on public employment. The social planner faces the same stochastic innovation process and exogenous death rate of firms/varieties as the market does. The social planner will only let high productivity varieties be produced as low productivity varieties are too expensive in terms of labour devoted to fixed costs of production. Let $\hat{M}$ and $\hat{\varphi}^{*}$ denote the mass of varieties and the exit threshold in the social planner optimum. The problem of the social planner can therefore be written

$$
\begin{aligned}
\max _{q(\varphi), \hat{\varphi}^{*}, \hat{M}} U & =\hat{M}^{\frac{\sigma}{\sigma-1}}\left[\int_{\hat{\varphi}^{*}}^{\infty} q(\varphi)^{\frac{\sigma-1}{\sigma}} \frac{g(\varphi)}{1-G\left(\hat{\varphi}^{*}\right)} d \varphi\right]^{\frac{\sigma}{\sigma-1}} \\
\text { s.t. } L-\hat{T} & =\hat{M}\left(F+\frac{\delta F_{E}}{1-G\left(\hat{\varphi}^{*}\right)}+\int_{\hat{\varphi}^{*}}^{\infty} \frac{q(\varphi)}{\varphi} \frac{g(\varphi)}{1-G\left(\hat{\varphi}^{*}\right)} d \varphi\right) .
\end{aligned}
$$

In optimum marginal rates of substitution will equal the corresponding marginal rates of transformation. Exploiting this condition for the marginal variety, we have

$$
\frac{q(\varphi)^{-\frac{1}{\sigma}}}{q\left(\hat{\varphi}^{*}\right)^{-\frac{1}{\sigma}}}=\frac{\hat{\varphi}^{*}}{\varphi} \Rightarrow q(\varphi)=q\left(\hat{\varphi}^{*}\right)\left(\frac{\hat{\varphi}^{*}}{\varphi}\right)^{-\sigma} .
$$

Inserting (A.1) and subsequently the labour constraint into the objective, we can rewrite the social planner problem as

$$
\max _{\hat{\varphi}^{*}, q\left(\hat{\varphi}^{*}\right)} U=(L-\hat{T})^{\frac{\sigma}{\sigma-1}} q\left(\hat{\varphi}^{*}\right)\left(\hat{\varphi}^{*}\right)^{-\sigma}\left[\frac{F\left(1-G\left(\varphi^{*}\right)\right)+\delta F_{E}}{\int_{\hat{\varphi}^{*}}^{\infty} \varphi^{\sigma-1} g(\varphi) d \varphi}+q\left(\hat{\varphi}^{*}\right)\left(\hat{\varphi}^{*}\right)^{-\sigma}\right]^{-\frac{\sigma}{\sigma-1}} .
$$

The optimality conditions read

$$
\begin{gathered}
\frac{d U}{d q\left(\hat{\varphi}^{*}\right)}=\frac{U}{q\left(\hat{\varphi}^{*}\right)}\left[\frac{\frac{F\left(1-G\left(\varphi^{*}\right)\right)+\delta F_{E}}{\int_{\hat{\varphi}^{*} \varphi^{\sigma-1} g(\varphi) d \varphi}-\frac{1}{\sigma-1} q\left(\hat{\varphi}^{*}\right)\left(\hat{\varphi}^{*}\right)^{-\sigma}}}{\frac{F\left(1-G\left(\varphi^{*}\right)\right)+\delta F_{E}}{\int_{\hat{\varphi}^{*}}^{\infty} \varphi^{\sigma-1} g(\varphi) d \varphi}+q\left(\hat{\varphi}^{*}\right)\left(\hat{\varphi}^{*}\right)^{-\sigma}}\right]=0 \\
\frac{d U}{d \hat{\varphi}^{*}}=-\frac{U}{\hat{\varphi}^{*}}\left[\sigma-\frac{\sigma}{\sigma-1} \frac{\sigma q\left(\hat{\varphi}^{*}\right)\left(\hat{\varphi}^{*}\right)^{-\sigma}+\frac{F g\left(\varphi^{*}\right) \hat{\varphi}^{*}}{\int_{\hat{\varphi}^{*}}^{\infty} \varphi^{\sigma-1} g(\varphi) d \varphi}-\frac{F\left(1-G\left(\varphi^{*}\right)\right)+\delta F_{E}}{\int_{\hat{\varphi}^{*}}^{\infty} \varphi^{\sigma-1} g\left(\hat{\varphi}^{*}\right) d \varphi} \frac{\varphi^{\sigma-1} g\left(\hat{\varphi}^{*}\right) \hat{\varphi}^{*}}{\int_{\hat{\varphi}^{*}} \varphi^{\sigma-1} g(\varphi) d \varphi}}{\frac{F\left(1-G\left(\varphi^{*}\right)+\delta F_{E}\right.}{\int_{\hat{\varphi}^{*}}^{\infty} \varphi^{\sigma-1} g(\varphi) d \varphi}+q\left(\hat{\varphi}^{*}\right)\left(\hat{\varphi}^{*}\right)^{-\sigma}}\right]=0 .
\end{gathered}
$$

Insert that $\frac{d U}{d q\left(\hat{\varphi}^{*}\right)}=0 \Rightarrow q\left(\hat{\varphi}^{*}\right)=\frac{\left(F\left(1-G\left(\varphi^{*}\right)\right)+\delta F_{E}\right)(\sigma-1)\left(\hat{\varphi}^{*}\right)^{\sigma}}{\int_{\hat{\varphi}^{*}}^{\infty} \varphi^{\sigma-1} g(\varphi) d \varphi}$ into $\frac{d U}{d \hat{\varphi}^{*}}=0$ to obtain that

$$
\int_{\hat{\varphi}^{*}}^{\infty}\left(\frac{\varphi}{\hat{\varphi}^{*}}\right)^{\sigma-1} g(\varphi) d \varphi-\left(1-G\left(\varphi^{*}\right)\right)=\frac{\delta F_{E}}{F} .
$$

By direct comparison with the exit threshold of the market equilibrium (7), it follows that $\hat{\varphi}^{*}=\varphi^{*}\left(0, \frac{\delta F_{E}}{F}, \sigma\right)$. We next show that consumption/production of 
each variety and the mass of varieties in the social planner solution coincide with those of the market equilibrium with no unit tax. From the demand functions (2), optimal prices (4) and by setting the unit tax equal to zero it follows that

$$
\frac{q(\varphi)}{q\left(\varphi^{*}\right)}=\frac{\left(\frac{p(\varphi)}{P}\right)^{-\sigma} \frac{E}{P}}{\left(\frac{p\left(\varphi^{*}\right)}{P}\right)^{-\sigma} \frac{E}{P}}=\left(\frac{\frac{1}{\varphi}+t}{\frac{1}{\varphi^{*}}+t}\right)^{-\sigma}=\left(\frac{\varphi^{*}}{\varphi}\right)^{-\sigma}
$$

implying that relative demand of each variety is the same in the market equilibrium as in the social planner solution, cf. (A.1). Turning to the level of demand, we have for the social planner solution that

$$
q\left(\hat{\varphi}^{*}\right)=\frac{\left(F\left(1-G\left(\varphi^{*}\right)\right)+\delta F_{E}\right)(\sigma-1)\left(\hat{\varphi}^{*}\right)^{\sigma}}{\int_{\hat{\varphi}^{*}}^{\infty} \varphi^{\sigma-1} g(\varphi) d \varphi} .
$$

Using that $\pi\left(\varphi^{*}\right)=q\left(\varphi^{*}\right)\left(\frac{p\left(\varphi^{*}\right)}{1+\tau}-\frac{1}{\varphi^{*} \varphi}-t\right)-F=0$, the pricing equation (4) and setting $t=0$, we find for the market equilibrium that

$$
q\left(\varphi^{*}\right)=\frac{F}{\left(\frac{p\left(\varphi^{*}\right)}{1+\tau}-\frac{1}{\varphi^{*}}\right)}=(\sigma-1) F \varphi^{*}=(\sigma-1) F\left(\varphi^{*}\right)^{\sigma}\left(\varphi^{*}\right)^{1-\sigma}
$$

Setting $t=0$ in the free entry condition determining the exit threshold (7), we find that

$$
\left(\varphi^{*}\right)^{1-\sigma}=\frac{\frac{\delta F_{E}}{F}+\left[1-G\left(\varphi^{*}\right)\right]}{\int_{\varphi^{*}}^{\infty} \varphi^{\sigma-1} g(\varphi) d \varphi}
$$

and substituting this into the expression for $q\left(\varphi^{*}\right)$, we find that

$$
q\left(\varphi^{*}\right)=(\sigma-1) F\left(\varphi^{*}\right)^{\sigma} \frac{\frac{\delta F_{E}}{F}+\left[1-G\left(\varphi^{*}\right)\right]}{\int_{\varphi^{*}}^{\infty} \varphi^{\sigma-1} g(\varphi) d \varphi}
$$

As $\varphi^{*}=\hat{\varphi}^{*}$, it follows from (A.2) and (A.3) that the level of demand is the same in the market equilibrium as for the social planner equilibrium. Finally, we need to show that the mass of varieties coincides. However, this follows directly from the full employment condition.

\section{Proof of Proposition 2}

From Proposition 1 we know that an ad valorem tax has no effect on the exit threshold $\left(\varphi^{*}\right)$ and therefore no effect on average productivity, cf. (8). Proposition 2 states that a unit tax reduces average productivity:

$$
\frac{d \bar{\varphi}}{d t}=\underbrace{\frac{\partial \bar{\varphi}}{\partial t}}_{-}+\underbrace{\frac{\partial \bar{\varphi}}{\partial \varphi^{*}}}_{+} \underbrace{\frac{d \varphi^{*}}{d t}}_{-}<0
$$


Proof. Note that $\frac{d \varphi^{*}}{d t}<0$ cf. Proposition 1, and $\frac{\partial \bar{\varphi}}{\partial \varphi^{*}}=\bar{\varphi} g\left(\varphi^{*}\right)\left(\frac{1}{\varphi^{*}}+t\right)^{-\sigma}\left[\frac{-1}{\int_{\varphi^{*}}^{\infty} \frac{\varphi}{\varphi^{*}}\left(\frac{1}{\varphi}+t\right)^{-\sigma} g(\varphi) d \varphi}+\frac{1}{\int_{\varphi^{*}}^{\infty}\left(\frac{1}{\varphi}+t\right)^{-\sigma} g(\varphi) d \varphi}\right]>0$

and

$$
\begin{aligned}
\frac{\partial \bar{\varphi}}{\partial t}= & -\sigma \bar{\varphi}\left[\frac{\int_{\varphi^{*}}^{\infty} \varphi\left(\frac{1}{\varphi}+t\right)^{-\sigma-1} g(\varphi) d \varphi}{\int_{\varphi^{*}}^{\infty} \varphi\left(\frac{1}{\varphi}+t\right)^{-\sigma} g(\varphi) d \varphi}-\frac{\int_{\varphi^{*}}^{\infty}\left(\frac{1}{\varphi}+t\right)^{-\sigma-1} g(\varphi) d \varphi}{\int_{\varphi^{*}}^{\infty}\left(\frac{1}{\varphi}+t\right)^{-\sigma} g(\varphi) d \varphi}\right] \\
= & \frac{-\sigma \int_{\varphi^{*}}^{\infty}\left(\frac{1}{\varphi}+t\right)^{-\sigma-1} g(\varphi) d \varphi}{\int_{\varphi^{*}}^{\infty}\left(\frac{1}{\varphi}+t\right)^{-\sigma} g(\varphi) d \varphi} \times \\
& {\left[\int_{\varphi^{*}}^{\infty} \varphi \frac{\left(\frac{1}{\varphi}+t\right)^{-\sigma-1} g(\varphi)}{\int_{\varphi^{*}}^{\infty}\left(\frac{1}{\varphi}+t\right)^{-\sigma-1} g(\varphi) d \varphi} d \varphi-\int_{\varphi^{*}}^{\infty} \varphi \frac{\left(\frac{1}{\varphi}+t\right)^{-\sigma} g(\varphi)}{\int_{\varphi^{*}}^{\infty}\left(\frac{1}{\varphi}+t\right)^{-\sigma} g(\varphi) d \varphi} d \varphi\right]<0, }
\end{aligned}
$$

where the sign is determined by the difference in average productivity computed with different weights, as $\int_{\varphi^{*}}^{\infty} \frac{\left(\frac{1}{\varphi}+t\right)^{-\sigma-1} g(\varphi)}{\int_{\varphi^{*}}^{\infty}\left(\frac{1}{\varphi}+t\right)^{-\sigma-1} g(\varphi) d \varphi} d \varphi=\int_{\varphi^{*}}^{\infty} \frac{\left(\frac{1}{\varphi}+t\right)^{-\sigma} g(\varphi)}{\int_{\varphi^{*}}^{\infty}\left(\frac{1}{\varphi}+t\right)^{-\sigma} g(\varphi) d \varphi} d \varphi=$ 1. Since $\frac{\left(\frac{1}{\varphi}+t\right)^{-\sigma-1} g(\varphi)}{\int_{\varphi^{*}}^{\infty}\left(\frac{1}{\varphi}+t\right)^{-\sigma-1} g(\varphi) d \varphi} \lessgtr \frac{\left(\frac{1}{\varphi}+t\right)^{-\sigma} g(\varphi)}{\int_{\varphi^{*}}^{\infty}\left(\frac{1}{\varphi}+t\right)^{-\sigma} g(\varphi) d \varphi}$ for $\varphi \lessgtr\left[\frac{\int_{\varphi^{*}}^{\infty}\left(\frac{1}{\varphi}+t\right)^{-\sigma} g(\varphi) d \varphi}{\int_{\varphi^{*}}^{\infty}\left(\frac{1}{\varphi}+t\right)^{-\sigma-1} g(\varphi) d \varphi}-t\right]^{-1}$, it follows that $\frac{\partial \bar{\varphi}}{\partial t}<0$.

\section{Homogenous firms}

Assume that all firms share the same marginal productivity $\varphi$. From the profit expression (5) it follows that

$$
\pi(\varphi)=\frac{1}{\sigma-1}\left(\frac{\sigma}{\sigma-1}\right)^{-\sigma} P^{\sigma-1} E(1+\tau)^{-\sigma}\left(\frac{1}{\varphi}+t\right)^{1-\sigma}-F .
$$

The price index becomes $P=M^{\frac{1}{1-\sigma}} \frac{\sigma}{\sigma-1}(1+\tau)\left(\frac{1}{\varphi}+t\right)$ and as $E=L$, we have from setting expected net profits equal to zero (free entry)

$$
\frac{\pi(\varphi)}{\delta}=F_{E} \Leftrightarrow M=\frac{L}{(1+\tau) \sigma\left(\delta F_{E}+F\right)} .
$$

Total tax revenue equals

$$
T=M q(\varphi)\left[t+\frac{\tau}{1+\tau} p(\varphi)\right]=L \frac{t \frac{\sigma-1}{\sigma}+\tau\left(\frac{1}{\varphi}+t\right)}{(1+\tau)\left(\frac{1}{\varphi}+t\right)}
$$


and utility equals

$$
U=\frac{L}{P}=\frac{\sigma-1}{\sigma} \frac{L\left(\frac{L}{\sigma\left(\delta F_{E}+F\right)}\right)^{\frac{1}{\sigma-1}}}{(1+\tau)^{\frac{\sigma}{\sigma-1}}\left(\frac{1}{\varphi}+t\right)}
$$

Collecting tax revenue $\hat{T}$ through a unit tax requires $t=\frac{\frac{\hat{T}}{L} \frac{\sigma}{\sigma-1}}{1-\frac{\hat{T}}{L} \frac{\sigma}{\sigma-1}} \frac{1}{\varphi}$ implying $U^{t}=\frac{\sigma-1}{\sigma}\left(1-\frac{\hat{T}}{L} \frac{\sigma}{\sigma-1}\right) L\left(\frac{L}{\sigma\left(\delta F_{E}+F\right)}\right)^{\frac{1}{\sigma-1}} \varphi$. Collecting the tax revenue through an ad valorem tax requires $\tau=\frac{\frac{\hat{T}}{L}}{1-\frac{\hat{T}}{L}}$ which in turn implies $U^{\tau}=\frac{\sigma-1}{\sigma}\left(1-\frac{\hat{T}}{L}\right)^{\frac{\sigma}{\sigma-1}} L\left(\frac{L}{\sigma\left(\delta F_{E}+F\right)}\right)^{\frac{1}{\sigma-1}} \varphi$. Relative welfare thus equals

$$
\frac{U^{\tau}}{U^{t}}=\frac{\left(1-\frac{\hat{T}}{L}\right)^{\frac{\sigma}{\sigma-1}}}{1-\frac{\hat{T}}{L} \frac{\sigma}{\sigma-1}}>1 \text { for } \hat{T}>0
$$

\section{Numerical solutions}

The following algorithm solves the model and computes welfare when the exogenous tax revenue is collected through a unit tax

1. Fix all exogenous variables: $\frac{\hat{T}}{L}, \sigma, \delta, F, F_{E}, g(\varphi), \tau=0$

2. For given $t$ determine $\varphi^{*}\left(t, \frac{\delta F_{E}}{F}, \sigma\right)$ from $(7)$

3. Calculate $\frac{\left.T\right|_{\tau=0}}{L}$ from (13) given $\varphi^{*}\left(t, \frac{\delta F_{E}}{F}, \sigma\right)$ and $t$

4. Iterate on $t$ until $\left|\frac{\left.T\right|_{\tau=0}}{L}-\frac{\hat{T}}{L}\right|<\varepsilon$

5. Next, calculate welfare from (11) using $\varphi^{*}\left(t, \frac{\delta F_{E}}{F}, \sigma\right)$ and $t$ obtained in step 2 through 4.

The following algorithm solves the model and computes welfare when the exogenous tax revenue is collected through an ad valorem tax.

1. Fix all exogenous variables: $\frac{\hat{T}}{L}, \sigma, \delta, F, F_{E}, g(\varphi), t=0$

2. Determine $\varphi^{*}\left(0, \frac{\delta F_{E}}{F}, \sigma\right)$ from $(7)$ and $\tau=\frac{\frac{\hat{T}}{L}}{1-\frac{\hat{T}}{L}}$ according to (12)

3. Next, calculate welfare from (11) using $\varphi^{*}\left(0, \frac{\delta F_{E}}{F}, \sigma\right)$ and $\tau$ from step 2 . 


\section{References}

[1] Anderson, Simon P. , André de Palma and Brent Kreider. 2001. "The efficiency of indirect taxes under imperfect competition". Journal of Public Economics, 81(2): 231-51.

[2] Axtell, Robert L. 2001. "Zipf Distribution of U. S. Firm Sizes". Science, 293(5536): 1818-20.

[3] Blackorby, Charles and Sushama Murty. 2007. "Unit versus ad valorem taxes: Monopoly in general equilibrium". Journal of Public Economics, 91(3-4): 817-22.

[4] Chaney, Thomas. 2007. "Distorted Gravity: The Intensive and Extensive Margins of International Trade". American Economic Review, 98(4): 170721.

[5] Delipalla, Sofia and Michael Keen. 1992. "The Comparison between Ad Valorem and Specific Taxation under Imperfect Competition". Journal of Public Economics, 49(3): 351-67.

[6] Dixit, Avinash K. and Joseph E. Stiglitz. 1977. "Monopolistic Competition and Optimum Product Diversity". American Economic Review, 67(3): 297-308.

[7] Doi, Junko and Koichi Futagami. 2004. "Commodity Taxation and the Effects of Entry: A Case of Variety Preferences". Journal of Economics, 83(3): 267-79.

[8] Dröge, Susanne and Philipp J.H. Schröder. 2009. "The welfare comparison of corrective ad valorem and unit taxes under monopolistic competition". International Tax and Public Finance, 16: 164-75.

[9] Dunne, T., M. Roberts and L. Samuelson. 1989. "The Growth and Failure of US Manufacturing Plants". Quaterly Journal of Economics, 104: 671-98.

[10] Helpman, Elhanan, Marc J. Melitz and Stephen R. Yeaple. 2004. "Export versus FDI with Heterogeneous Firms". American Economic Review, 94(1): $300-16$.

[11] Hamilton, Stephen F. 1999. "Tax Incidence under Oligopoly: A Comparison of Policy Approaches". Journal of Public Economics, 71: 233-45.

[12] Hopenhayn, Hugo A. 1992. "Entry, Exit, and Firm Dynamics in Long Run Equilibrium". Econometrica, 60(5): 1127-50.

[13] Keen, Michael. 1998. "The Balance between Specific and Ad Valorem Taxation". Fiscal Studies, 19: 1-37.

[14] Luttmer, Erzo G. J. 2007. "Selection, Growth, and the Size Distribution of Firms". Quarterly Journal of Economics, 122(3): 1103-44. 
[15] Melitz, Marc J. 2003. "The Impact of Trade on Intra-Industry Reallocations and Aggregate Industry Productivity". Econometrica, 71(6): 1695-1725.

[16] Pirttilä, Jukka. 2002. "Specific versus ad valorem Taxation and Externalities". Journal of Economics, 76(2): 177-87.

[17] Schröder, Philipp J.H. 2004. "The Comparison between Ad Valorem and Unit Taxes under Monopolistic Competition". Journal of Economics, 83(3): $281-92$.

[18] Simon, Herbert A. and Charles P. Bonini. 1958. "The Size Distribution of Business Firms". American Economic Review, 48(4): 607-17.

[19] Suits, D.B. and R.A. Musgrave. 1953. "Ad Valorem and Unit Taxes Compared". Quarterly Journal of Economics, 67: 598-604.

[20] Torregrosa, Ramon J. 2008. "Macroeconomic effects of an indirect tax substituion". Journal of Economics, 94: 199-221.

[21] Wang, Henry X. and Jingang Zhao. 2009. "On the efficiency of indirect taxes in differentiated oligopolies with asymmetric costs". Journal of Economics, 96: 223-39.

[22] Wicksell, K. 1896. "Taxation in the Monopoly Case". Translation from the original, in: Musgrave and Shoups (Eds.), 1959. Readings in the Economics of Taxation, Irwin, Homewood, IL. 

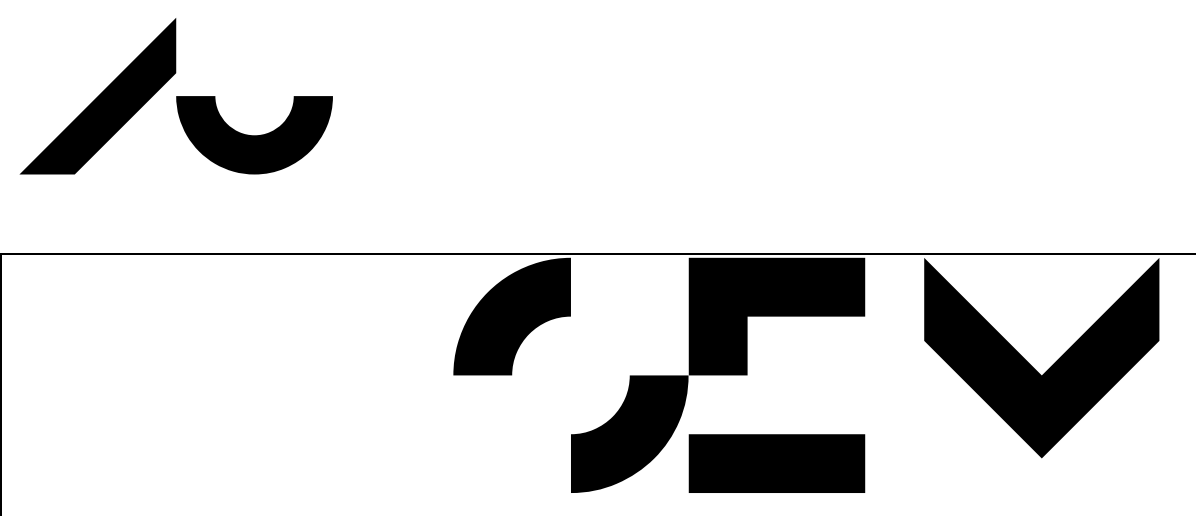

Economics Working Paper

2010-10

\section{Ad valorem versus unit taxes: Monopolistic competition, heterogeneous firms, and intra- industry reallocations}

Philipp J.H. Schröder and Allan Sørensen

Bartholins Allé 10, Building 1322

DK-8000 Aarhus C - Denmark

Phone +4589421610

Mail: oekonomi@econ.au.dk

Web: www.econ.au.dk 


\section{Economics Working Paper}

2009-16: Torben M. Andersen and Joydeep Bhattacharya: Unfunded pensions and endogenous labor supply

2009-17: Hristos Doucouliagos and Martin Paldam: Development Aid and Growth: An association converging to zero

2009-18: Christian Bjørnskov and Martin Paldam: The spirits of capitalism and socialism. A cross-country study of ideology

2010-1: $\quad$ Laurent Callot and Martin Paldam: Natural funnel asymmetries. A simulation analysis of the three basic tools of meta analysis

2010-2: $\quad$ Allan Sørensen: Welfare Effects of Trade Liberalization with Intra-industry Reallocations: The Importance of Preferences and Market Failures

2010-3: $\quad$ Marianne Simonsen, Lars Skipper and Niels Skipper: Price Sensitivity of Demand for Prescription Drugs: Exploiting a Regression Kink Design

2010-4: $\quad$ Torben M. Andersen and Allan Sørensen: Product market integration, rents and wage inequality

2010-5: John Kennes and Daniel le Maire: Coordination Frictions and Job Heterogeneity: A Discrete Time Analysis

2010-6: $\quad$ Philipp J.H. Schröder and Allan Sørensen: The Theoretical Equivalent of Empirically Measurable Exporter Productivity when Firms are Heterogeneous

2010-7: $\quad$ Nabanita Datta Gupta and Marianne Simonsen: Effects of Universal Child Care Participation on Pre-teen Skills and Risky Behaviors

2010-8: $\quad$ Olaf Posch and Timo Trimborn: Numerical solution of continuous-time DSGE models under Poisson uncertainty

2010-9: Torben M. Andersen and Allan Sørensen: Globalization, tax distortions and public sector retrenchment

2010-10: $\quad$ Philipp J.H. Schröder and Allan Sørensen: Ad valorem versus unit taxes: Monopolistic competition, heterogeneous firms, and intra-industry reallocations 